\title{
PENGARUH PENAMBAHAN SERAT KACA PADA BAHAN BASIS GIGI TIRUAN NILON TERMOPLASTIK DAUR ULANG TERHADAP KEKUATAN TRANSVERSAL DAN MODULUS ELASTISITAS
}

\author{
Siti Habibah Safina, Siti Wahyuni \\ Departemen Prostodonsia, Fakultas Kedokteran Gigi, Universitas Sumatera Utara \\ Jl. Alumni No. 2 Kampus USU Medan 20155 \\ e-mail: sitihabibahsafina@gmail.com
}

\begin{abstract}
KATA KUNCI
nilon, serat kaca, kekuatan transversal, modulus elastisitas
\end{abstract}

\begin{tabular}{l}
\hline KEYWORDS \\
\hline nylon, glass fiber, \\
transverse strength, \\
modulus of elasticity
\end{tabular}

\begin{abstract}
ABSTRAK
Pendahuluan: Nilon diperkenalkan dalam pembuatan gigi tiruan pada tahun 1950-an. Nilon dimanipulasi dengan teknik injection molding. Teknik tersebut menghasilkan spru yang dapat didaur ulang akan tetapi menyebabkan penurunan sifat mekanis nilon seperti kekuatan transversal dan modulus elastisitas. Untuk mengatasi penurunan sifat tersebut dilakukan modifikasi dengan penambahan bahan kompatibilisasi yaitu nilon murni dan serat kaca, diharapkan dapat meningkatkan kekuatan transversal dan modulus elastisitas. Metode: Rancangan penelitian ini adalah eksperimental laboratoris yaitu posttest only control design. Sampel pada penelitian ini adalah nilon termoplastik berbentuk batang uji dengan ukuran 64 x 10 x 3,3mm. Sebanyak 27 sampel untuk 3 kelompok kemudian dilakukan uji three point bending. Nilai kekuatan transversal dianalisis dengan uji Kruskal-Wallis dan modulus elastisitas dengan uji ANOVA untuk melihat pengaruh penambahan serat kaca pada kombinasi $60 \%$ nilon murni $40 \%$ nilon daur dan nilon daur ulang $100 \%$, dilanjutkan dengan uji Mann-Whitney dan LSD untuk melihat perbedaan nilai antar kelompok. Hasil: Penelitian ini menunjukkan bahwa terdapat perbedaan yang signifikan pada kekuatan transversal dan modulus elastisitas antara nilon murni dan nilon daur ulang dengan penambahan serat kaca dengan nilai $\mathrm{p}=0,038(\mathrm{p}<0,05)$ dan $\mathrm{p}=0,0001(\mathrm{p}<0,05)$, nilon murni dan nilon kombinasi dengan penambahan serat kaca dengan nilai $\mathrm{p}=0,0001(\mathrm{p}<0,05)$ dan $\mathrm{p}=0,0001(\mathrm{p}<0,05)$, serta nilon kombinasi dan nilon daur ulang dengan penambahan serat kaca dengan nilai $\mathrm{p}=0,0001(\mathrm{p}<0,05)$ dan $\mathrm{p}=0,0001(\mathrm{p}<0,05)$. Simpulan: Nilon kombinasi yang ditambahkan serat kaca memiliki nilai yang lebih baik dibandingkan nilon murni.
\end{abstract}


using ANOVA, then continued by using Mann-Whitney and LSD test to see the difference in values between groups. Result: The result of this study showed that there is a significant difference in transverse strength and modulus of elasticity between a combination of $60 \%$ virgin nylon $40 \%$ recycled nylon and recycled nylon only with the addition of glass fiber, the $p$-value $=0,038(p<0,05)$ and $p=0,0001$ $(p<0,05)$, virgin nylon and nylon combination with the addition of glass fiber, the $p$-value $=0,0001(p<0,05)$ and $p=0,0001(p<$ 0,05 ), and also nylon combination with the addition of glass fiber and recycled nylon with the addition of glass fiber, the $p$-value $=0,0001$ $(p<0,05)$ and $p=0,0001$ ( $p<0,05)$. Conclusion: Nylon combination with the addition of glass fiber has a better value than virgin nylon.

\section{PENDAHULUAN}

Basis gigi tiruan adalah bagian dari gigi tiruan yang bersandar pada mukosa rongga mulut dan merupakan tempat melekatnya anasir gigi tiruan. Basis gigi tiruan membantu mendistribusikan seluruh tekanan gigi tiruan ke jaringan pendukung. ${ }^{1,2}$ Bahan yang digunakan untuk membuat basis gigi tiruan dapat dibedakan menjadi dua kelompok yaitu logam dan non logam. ${ }^{2}$ Bahan basis gigi tiruan non logam terdiri atas bahan termoset dan termoplastik. Contoh dari bahan termoplastik adalah asetal termoplastik, akrilik termoplastik, polikarbonat termoplastik dan nilon termoplastik. $^{2}$.

Beberapa tahun terakhir, nilon termoplastik mulai menarik perhatian sebagai bahan basis gigi tiruan. Nilon adalah nama generik dari polimer termoplastik yang termasuk kedalam golongan polimer poliamida. Poliamida ini diproduksi dengan reaksi kondensasi antara diamin NH2-(CH2)6-NH2 dan dibasic acid $\mathrm{CO} 2 \mathrm{H}-(\mathrm{CH} 2) 4-\mathrm{COOH}$. Nilon poliamida pertama kali diperkenalkan dalam pembuatan gigi tiruan pada tahun 1950-an dan sekarang menjadi alternatif dari metil metakrilat karena dapat meningkatkan sifat estetis, ketahanan terhadap panas bahan kimia, dan aman untuk pasien yang alergi monomer metakrilat dan penguat logam. ${ }^{3}$

Nilon memiliki beberapa sifat mekanis seperti kekuatan transversal dan modulus elastisitas. Kekuatan transversal untuk bahan basis gigi tiruan termoplastik berdasarkan ISO 20795-1: 2013 tidak boleh kurang dari $65 \mathrm{MPa}^{4}{ }^{4}$ Pada penelitian yang dilakukan oleh Soygun dkk (2013) menunjukkan bahwa bahan basis gigi tiruan poliamida memiliki kekuatan transversal terbesar yaitu 117,22 \pm 37,8 MPa. Modulus elastisitas pada gigi tiruan berdasarkan standar ISO adalah 2000 MPa. Penelitian yang dilakukan oleh Song (2019) meununjukkan nilai modulus elastisitas bahan basis gigi tiruan poliamida sebesar 1209,95 $\mathrm{MPa}^{5}$ Nilon merupakan polimer amida sehingga bersifat hidrofilik. Sifat hidrofilik yang disebabkan oleh adanya ikatan amida mengakibatkan tingginya penyerapan air pada nilon, semakin pendek ikatannya maka akan semakin mudah menyerap air. ${ }^{6}$ Air yang diserap akan 
bertindak sebagai plasticizer yang akan menyebabkan penurunan sifat-sifat mekanis. ${ }^{7}$ Teknik manipulasi nilon termoplastik adalah dengan mengggunakan teknik injection molding. Teknik injection molding menghasilkan spru yang tidak digunakan lagi setelah proses pembuatan gigi tiruan selesai. Spru yang tidak digunakan lagi akan menjadi limbah yang dapat mencemari lingkungan. ${ }^{8}$ Oleh karena itu perlu dilakukan daur ulang terhadap material polimer tersebut. Ada beberapa metode dalam melakukan daur ulang yaitu, metode daur ulang primer (inplant), metode daur ulang sekunder (mekanis), metode daur ulang tersier (kimiawi) dan metode daur ulang kuartener (energy recovery). ${ }^{9}$ Metode daur ulang mekanis paling banyak digunakan karena lebih ekonomis dan efisien dibandingkan dengan metode yang lain. ${ }^{10}$ Metode daur ulang mekanis memiliki kekurangan yaitu terjadi penurunan sifat pada setiap prosesnya, karena berat molekul dari polimer yang didaur ulang berkurang disebabkan karena terpotongnya ikatan rantai polimer. ${ }^{9}$ Penelitian yang dilakukan oleh Soja dan Norbert (2013) menunjukkan terjadinya penurunan pada modulus elastisitas dan kekuatan transversal poliamida 6.6 yang tidak digunakan lagi. Modulus elastisitas nilon 6.6 sebelum dilakukan daur ulang $3226 \mathrm{MPa}$ dan terjadi penurunan menjadi $1022 \mathrm{MPa}$ setelah didaur ulang. Soja dan norbert juga melakukan penelitian terhadap kekuatan transversal dan modulus elastisitas poliamida
6.6 daur ulang dengan penambahan serat kaca, hasilnya menunjukkan terjadi penurunan dari 248,5 $\mathrm{MPa}$ dan $5622 \mathrm{MPa}$ menjadi $166 \mathrm{MPa}$ dan $3416 \mathrm{MPa} .{ }^{11}$

Ada dua cara yang dapat dilakukan untuk mengatasi hal tersebut, diantaranya dengan cara modifikasi, yaitu memodifikasi polimer daur ulang dengan bahan polimer lain atau bahan polimer itu sendiri dan cara compatibilisation yaitu penambahan bahan kompatibilisasi. Modifikasi merupakan strategi yang sangat baik dalam meningkatkan ketahanan fraktur dengan peningkatan interfacial adhesion. Penelitian yang dilakukan oleh Lumban Gaol (2016) menunjukkan bahwa penambahan $60 \%$ nilon murni ke dalam nilon daur ulang menghasilkan nilai kekuatan transversal yang hampir sama baiknya dengan nilon murni. ${ }^{12}$ Penelitian lain yang dilakukan oleh Harahap (2017) menunjukkan hasil nilai modulus elastisitas yang tidak signifikan antara nilon daur ulang dan nilon daur ulang kombinasi $60 \%$ nilon murni dan $40 \%$ nilon daur ulang. ${ }^{13}$ Metode lain yang umum digunakan untuk memperkuat basis gigi tiruan polimer adalah dengan menambahkan bahan penguat seperti penguat logam dan berbagai jenis serat, salah satunya adalah serat kaca. ${ }^{14}$ Serat kaca merupakan fiber yang paling sering digunakan karena mudah dimanipulasi, memiliki ikatan yang baik dengan polimer dan estetik. ${ }^{15} \quad$ Penelitian-penelitian sebelumnya melaporkan bahwa penambahan serat kaca dalam berbagai bentuk dapat 
meningkatkan kekuatan transversal basis gigi tiruan. Selain bentuk serat, distribusi serat dalam struktur polimer yang dipengaruhinya, ukuran serat dan kandungan serat juga sangat memengaruhi. ${ }^{16}$

Serat kaca yang paling sering digunakan adalah E-glass dan S-glass. E-glass terbuat dari kaca aluminoborosilikat dengan konsentrasi alkali oksida kurang dari $1 \mathrm{wt} \%$. E-glass memiliki beberapa kelebihan diantaranya adalah harganya yang murah, sudah banyak digunakan dalam berbagai produksi, tidak mudah terbakar, tahan panas, dan dapat mempertahankan sifat kekuatannya dalam berbagai kondisi. ${ }^{17}$ Penelitian yang dilakukan oleh Ariyani (2013) melaporkan bahwa penambahan serat kaca potongan kecil ukuran $3 \mathrm{~mm}$ dengan konsentrasi 1\% menghasilkan penurunan penyerapan air paling baik pada nilon termoplastik, dan juga terjadi peningkatan pada kekuatan mekanis nilon termoplastik tersebut. ${ }^{18}$

Maka dari itu, penelitian ini bertujuan untuk mengetahui pengaruh penambahan serat kaca pada nilon daur ulang dan kombinasi terhadap kekuatan transversal dan modulus elastisitas bahan basis gigi tiruan nilon termoplastik.

\section{METODE}

Rancangan penelitian yang digunakan adalah ekperimental laboratoris. Penelitian ini dilakukan di Unit Jasa Industri Fakultas Kedokteran Gigi Universitas Sumatera Utara, Laboratorium Material Test Politeknik
Teknologi Kimia Industri dan Laboratorium Magister Teknik Mesin Universitas Sumatera Utara. Sampel pada penelitian ini adalah nilon termoplastik (kelompok A), nilon termplastik daur ulang dengan penambahan serat kaca (kelompok B) dan nilon termoplastik daur ulang kombinasi $60 \%$ murni dan $40 \%$ daur ulang dengan penambahan serat kaca (kelompok C). Serat kaca yang digunakan adalah jenis E-glass potongan kecil ukuran $3 \mathrm{~mm}$ dengan konsentrasi 1\% Ukuran model induk yang akan digunakan untuk pembuatan sampel kekuatan transversal dan modulus elastisitas adalah $64 \mathrm{~mm} \times(10 \pm 0,2) \mathrm{mm} \times(3,3 \pm 0,2) \mathrm{mm}$ (International Standards Organization No 1567) dibagi menjadi 3 kelompok dengan jumlah sampel tiap kelompok adalah 9.

Pembuatan sampel dilakukan dengan teknik injection molding yaitu dengan cara dilelehkan dan diinjeksikan ke dalam kuvet di bawah tekanan. Kuvet disiapkan untuk proses injeksi kemudian furnace dinyalakan hingga panas suhu $\pm 210^{\prime} \mathrm{C}$. Setelah itu cartridge dimasukkan ke dalam furnace selama \pm 15 menit agar butiran termoplastik dalam cartridge mencair. Bahan dalam cartridge diinjeksi ke dalam mold selagi panas kemudian dibiarkan di bawah tekanan selama 3 menit dan biarkan selama 30 menit hingga mengeras dan kemudian dipoles. Proses pembuatan sampel pada seluruh kelompok adalah sama, perbedaannya terdapat pada isi dalam cartridge yang akan diinjeksikan. Untuk sampel kelompok B 
menggunakan nilon daur ulang dengan penambahan serat kaca dan kelompok $\mathrm{C}$ menggunakan $60 \%$ nilon murni dan $40 \%$ nilon daur ulang dengan penambahan serat kaca.

Pengolahan nilon daur ulang. Nilon sisa (spru) dicuci menggunakan air yang bersih atau aquades, kemudian dipotong dengan pisau cutter atau gunting menjadi bentuk serpihan dibentuk menjadi bagian-bagian yang kecil. Bahan-bahan asing yang dapat mengontaminasi disingkirkan dan dipisahkan dari bahan yang akan didaur ulang. Nilon sisa yang sudah dicuci dikeringkan didalam desikator selama 24 jam dengan suhu $37^{\circ} \mathrm{C}$, pengeringan yang dilakukan minimal harus 6 jam untuk mendapatkan hasil yang lebih baik.

Untuk pemanipulasian serat kaca, peratama perat kaca ditimbang sebanyak $1 \%$ dari berat nilon dimasukkan dalam cairan silane coupling agent (Gamma methacrylopropytrimethoxysilane / MPS), kemudian dikeringkan dengan suhu kamar selama 40 menit dan kemudian dimasukkan ke dalam oven pemanas selama 1 jam pada suhu $115^{\circ} \mathrm{C}$. Serat kaca dimasukkan dengan teknik layer by layer.

Setelah sampel dipoles, batang uji nilon termoplastik diberi nomor pada kedua ujungnya kemudian dilakukan pengujian. Pengujian kekuatan transversal dan modulus elastisitas dilakukan dengan menggunakan alat Universal Testing Machine. Prosedur yang akan dilakukan adalah siapkan batang uji nilon termoplastik dengan ukuran yang sama dengan uji kekuatan transversal, beri nomor dan hitung jarak antara penampangnya, kemudian atur jarak tumpuan yaitu sebesar $50 \mathrm{~mm}$ lalu batang uji dipasang pada alat tersebut. Pembebanan diberikan di tengah-tengah jarak sampel secara berkelanjutan. Pada pengukuran kekuatan transversal sampel diuji hingga mengalami fraktur untuk memperoleh nilai maksimum bahan dalam menerima beban. Pengujian modulus elastisitas, pembebanan maksimum dilakukan hingga sample mengalami keretakan. Pengujian modulus elastisitas ini dilakukan untuk mengetahui lenturan yang akan terjadi dari pembebanan yang diberikan.

\section{HASIL}

Hasil uji kekuatan transversal dan modulus elastisitas dengan menggunakan universal testing machine dan besar beban dinyatakan dengan satuan MPa. 
Tabel 1. Nilai kekuatan transversal dan modulus elastisitas nilon murni, nilon daur ulang dengan penambahan serat kaca dan nilon kombinasi dengan penambahan serat kaca

\begin{tabular}{|c|c|c|c|c|c|c|}
\hline \multirow{2}{*}{$\begin{array}{c}\text { No. } \\
\text { sampel }\end{array}$} & \multicolumn{2}{|c|}{$\begin{array}{c}\text { Kelompok A } \\
\text { (nilon termoplastik murni) }\end{array}$} & \multicolumn{2}{|c|}{$\begin{array}{c}\text { Kelompok B } \\
\text { (nilon daur ulang) }\end{array}$} & \multicolumn{2}{c|}{$\begin{array}{c}\text { Kelompok C } \\
\text { (nilon kombinasi) }\end{array}$} \\
\cline { 2 - 7 } & $\begin{array}{c}\text { Kekuatan } \\
\text { transversal }\end{array}$ & $\begin{array}{c}\text { Modulus } \\
\text { elastisitas }\end{array}$ & $\begin{array}{c}\text { Kekuatan } \\
\text { transversal }\end{array}$ & $\begin{array}{c}\text { Modulus } \\
\text { elastisitas }\end{array}$ & $\begin{array}{c}\text { Kekuatan } \\
\text { transversal }\end{array}$ & $\begin{array}{c}\text { Modulus } \\
\text { elastisitas }\end{array}$ \\
\hline 1 & $85,46^{* *}$ & 903,49 & 73,18 & 903,49 & 100,42 & 903,49 \\
\hline 2 & 77,99 & 824,35 & $80,57 * *$ & 824,35 & $89,28 *$ & 824,35 \\
\hline 3 & 77,57 & 798,27 & 72,92 & 798,27 & 97,08 & 798,27 \\
\hline 4 & 74,22 & $779,14 *$ & 61,15 & $779,14 *$ & $100,67 * *$ & $779,14 *$ \\
\hline 5 & 84,05 & 930,44 & 59,90 & 930,44 & 98,21 & 930,44 \\
\hline 6 & $72,62 *$ & 899,14 & 76,29 & 899,14 & 97,37 & 899,14 \\
\hline 7 & 74,59 & $1068,71 * *$ & 77,52 & $1068,71 * *$ & 94,46 & $1068,71 * *$ \\
\hline 8 & 81,44 & 941,75 & $49,89 *$ & 941,75 & 99,24 & 941,75 \\
\hline 9 & 75,91 & 1024,36 & 73,35 & 1024,36 & 92,41 & 1024,36 \\
\hline$\overline{\mathrm{X}}+$ SD & $78,20 \pm 4,51$ & $907,73 \pm 97,94$ & $69,41 \pm 10,12$ & $907,73 \pm 97,94$ & $96,57 \pm 3,82$ & $907,73 \pm 97,94$ \\
\hline
\end{tabular}

Tabel 1 menunjukkan hasil nilai, rerata, dan standar deviasi kekuatan transversal dan modulus elastisitas tiap kelompok. Nilai kekuatan transversal tertinggi diantara kelompok A, B dan C adalah 100,67 MPa terdapat pada kelompok $\mathrm{C}$ sedangkan untuk nilai terendah terdapat pada kelompok B dengan nilai 49,89 MPa. Nilai modulus elastisitas tertinggi diantara kelompok A, B dan $\mathrm{C}$ adalah 1691,32 MPa terdapat pada kelompok $\mathrm{C}$ sedangkan untuk nilai terendah terdapat pada kelompok $\mathrm{B}$ dengan nilai 516,52 MPa.

Tabel 2. Hasil uji Kruskal-Wallis

\begin{tabular}{|c|c|c|}
\hline \multirow{2}{*}{ Kelompok } & \multirow{n}{*}{} & Kekuatan Transversal \\
\cline { 3 - 3 } & & $\mathrm{p}$ \\
\hline A dan B & 9 & $0,038^{*}$ \\
\hline B dan C & 9 & $0,0001^{*}$ \\
\hline A dan C & 9 & $0,0001^{*}$ \\
\hline
\end{tabular}

Berdasarkan hasil uji Kruskal-Wallis menunjukkan hasil perbedaan yang signifikan antara Kelompok A, B dan C ( p=0,0001, p<0,05) untuk nilai kekuatan transversal (Tabel 2)
Tabel 3. Hasil uji ANOVA

\begin{tabular}{|c|c|c|c|}
\hline \multirow{2}{*}{ Kelompok } & \multirow{2}{*}{$\mathrm{n}$} & \multicolumn{2}{|c|}{ Kekuatan transversal } \\
\cline { 3 - 3 } & & $\overline{\mathrm{X}} \pm \mathrm{SD}$ & $\mathrm{p}$ \\
\hline $\mathrm{A}$ & 9 & $78,20 \pm 4,51$ & \multirow{2}{*}{$0,0001^{*}$} \\
\hline $\mathrm{B}$ & 9 & $69,41 \pm 10,12$ & \\
\hline $\mathrm{C}$ & 9 & $96,57 \pm 3,82$ & \\
\hline
\end{tabular}

Berdasarkan hasil uji ANOVA menunjukkan hasil perbedaan yang signifikan antara Kelompok A, B dan C ( $\mathrm{p}=0,0001, \mathrm{p}<0,05)$ untuk modulus elastisitas(Tabel 3).

Tabel 4. Hasil uji Mann-withney

\begin{tabular}{|c|c|c|}
\hline \multirow{2}{*}{ Kelompok } & $\mathrm{n}$ & Modulus elastisitas \\
\cline { 3 - 3 } & & $\mathrm{p}$ \\
\hline A dan B & 9 & $0,038^{*}$ \\
\hline B dan C & 9 & $0,0001^{*}$ \\
\hline A dan C & 9 & $0,0001^{*}$ \\
\hline
\end{tabular}

Berdasarkan hasil uji Mann-Withney terlihat perbedaan bermakna antara kelompok A dan B, B dan C, serta A dan C $(\mathrm{p}<0,05)$ (Tabel 4).

Tabel 5. Hasil uji LSD

\begin{tabular}{|c|c|c|}
\hline \multirow{2}{*}{ Kelompok } & $\mathrm{n}$ & Modulus Elastisitas \\
\cline { 3 - 3 } & & $\mathrm{p}$ \\
\hline A dan B & 9 & $0,0001^{*}$ \\
\hline B dan C & 9 & $0,0001^{*}$ \\
\hline A dan C & 9 & $0,0001^{*}$ \\
\hline
\end{tabular}


Berdasarkan hasil uji $L S D$ terlihat perbedaan bermakna antara kelompok A dan B, B dan $C$, serta A dan C $(p<0,05)$ (Tabel 5).

\section{PEMBAHASAN}

Rancangan penelitian yang digunakan pada penelitian ini adalah eksperimental laboratoris yaitu post-test only control design yang bertujuan untuk mengetahui pengaruh penambahan serat kaca pada nilon daur ulang dan nilon kombinasi $60 \%$ murni dan $40 \%$ nilon daur ulang terhadap kekuatan transversal dan modulus elastisitas basis gigi tiruan nilon termoplastik dengan cara memberi perlakuan kepada satu atau lebih kelompok eksperimen kemudian hasil dari kelompok yang diberi perlakuan dibandingkan dengan kelompok kontrol (kelompok nilon murni).

Pada kelompok A, B dan C nilai kekuatan transversal yang diperoleh sudah mencukupi nilai standar ISO yaitu $65 \mathrm{MPa}$. Pada kelompok B nilai yang diperoleh lebih rendah dibandingkan dengan kelompok A. Penelitian yang dilakukan oleh Song (2019) meununjukkan nilai modulus elastisitas bahan basis gigi tiruan poliamida sebesar 1209,95 MPa. $^{5} \quad$ Penelitian lain yang dilakukan oleh Wieckiewicz (2014) menunjukkan nilai modulus elastisitas bahan basis gigi tiruan poliamida sebesar 1084 MPa. ${ }^{19}$ Pada penlitian ini nilai modulus elastisitas yang diperoleh mendekati nilai tersebut yaitu kelompok A sebesar 907,73
MPa dan yang tertinggi adalah kelompok $\mathrm{C}$ yaitu sebesar 1515,47 MPa.

Berdasarkan hasil penelitian tersebut diperoleh nilai kekuatan transversal dan modulus elastisitas yang bervariasi, hal ini disebabkan oleh beberapa hal yang memengaruhi proses pembuatan sampel antara lain microporosity dan macroporosity yang tidak terlihat pada saat proses injeksi dan ukuran nilon daur ulang yang digunakan pada saat penelitian. Porositas ini akan menyebabkan terbentuknya rongga sehingga terdapat ruang kosong pada sampel. Porositas ini akan menyebabkan berkurangnya kepadatan suatu bahan yang akan berdampak pada terjadinya penurunan sifat mekanis dari bahan. ${ }^{12}$ Persentase nilon daur ulang yang digunakan juga dapat menyebabkan nilai sampel yang diperoleh bervariasi. Kelompok B memiliki perbedaan nilai yang signifikan dengan kelompok A. Pada kelompok B nilon daur ulang yang digunakan memiliki persentase yang besar yaitu 100\%. Pada penelitian Meyabadi dkk (2010) yang melakukan proses daur ulang dengan mengkombinasikan nilon daur ulang dengan nilon termoplastik murni. Hasilnya menunjukkan semakin besar persentase nilon daur ulang yang ditambahkan maka semakin tinggi pola penurunan pada transition glass temperature ( $\mathrm{Tg}), \mathrm{Tg}$ yang mengalami penurunan akan menyebabkan ikatan hidrogen melemah sehingga ruang amorphous meningkat dan kristalin menurun sehingga menyebabkan penurunan dari sifat 
mekanis sampel. ${ }^{20}$ Pada saat proses daur ulang terjadi pemotongan rantai C-C (chain scission), atom $\mathrm{H}$ masuk kedalam rantai dan berikatan dengan atom $\mathrm{C}$ sehingga rantai panjang yang sebelumnya $\mathrm{CH} 2-\mathrm{CH} 2-\mathrm{CH} 2$ akan terpotong menjadi $\mathrm{CH} 3-\mathrm{CH} 3$. Hal tersebut mengakibatkan rantai polimer pada nilon menjadi lebih pendek dan ikatan rantai menjadi lemah dan tidak teratur sehingga ruang inter molekul merengggang akibatnya kristalin pada nilon berkurang dan menyebabkan terjadinya penurunan pada sifat mekanis. ${ }^{11}$ Kelompok C merupakan kombinasi $60 \%$ nilon murni dan $40 \%$ nilon daur ulang. Persentase nilon daur ulang kelompok $\mathrm{C}$ lebih kecil dibandingkan dengan kelompok B. Penelitian Buccela dkk (2012) menunjukkan bahwa penambahan nilon murni ke dalam nilon daur ulang menghasilkan struktur nilon yang lebih baik. Pada analisis terminal grup terlihat peningkatan berat molekul ketika nilon murni ditambahkan pada nilon daur ulang. ${ }^{21}$ Berat molekul yang meningkat menyebabkan ikatan rantai polimer menjadi lebih baik oleh karena tingginya tekanan ikatan Van Der Waals mengakibatkan kekuatan suatu polimer menjadi lebih tinggi. ${ }^{22}$ Penambahan nilon murni kedalam nilon daur ulang juga mengakibatkan terjadinya reaksi chain extender sehingga menghasilkan peningkatan pada kristalin. Chain extender bertujuan untuk mengurangi cabang dari ikatan yang terbentuk sehingga kepadatan dari polimer yang dihasilkan tidak jauh berbeda dengan polimer murni. ${ }^{21}$ Penelitian yang dilakukan oleh Lumban Gaol (2016) menunjukkan bahwa penambahan $60 \%$ nilon murni kedalam nilon daur ulang menghasilkan nilai kekuatan transversal yang hampir sama baiknya dengan nilon murni. ${ }^{12}$

Penambahan serat kaca pada kelompok C menyebabkan nilai kekuatan transversal pada kelompok $\mathrm{C}$ lebih tinggi dan memiliki perbedaan yang signifikan dibandingkan dengan kelompok A. Serat kaca akan membentuk ikatan kimia dengan nilon termoplastik dengan bantuan silane coupling agent, sehingga dapat mengisi rongga kosong pada matriks. ${ }^{23}$ Serat kaca yang digunakan bersama dengan silane coupling agent dapat membentuk adhesi yang baik dengan polimer nilon termoplastik. Pengaruh penambahan bahan pengisi seperti serat kaca pada polimer semi kristalin adalah memodifikasi kemampuan kristalinasi dari matriks polimer sehingga derajat kristalin matriks polimer meningkat. Peningkatan derajat kristalin mengakibatkan kekuatan dari polimer tersebut juga meningkat, karena pada fase kristalin ikatan intermolekul menjadi lebih kuat. $^{23,24}$ Penelitian yang dilakukan oleh Yoges (2015) melaporkan bahwa penambahan serat kaca potongan kecil ukuran $3 \mathrm{~mm}$ dengan konsentrasi $1 \%$ menghasilkan penurunan penyerapan air paling baik pada nilon termoplastik, dan terjadi peningkatan pada nilai kekuatan transversal dan modulus elastisitas nilon termoplastik. ${ }^{25}$ 


\section{KESIMPULAN}

Pada penelitian ini terlihat bahwa penambahan serat kaca pada nilon kombinasi $60 \%$ nilon murni dan $40 \%$ nilon daur ulang menghasilkan nilai kekuatan transversal dan modulus elastisitas yang lebih baik dibandingkan dengan nilon murni sehingga dapat digunakan sebagai bahan basis gigi tiruan karena nilai kekuatan transversal dan modulus elastisitasnya lebih baik dibandingkan dengan nilon murni.

\section{DAFTAR PUSTAKA}

1. Carr AB., Brownman DT, McCracken's Removable Partial Prosthodontics, $11^{\text {th }}$ ed, Elsevier, Canada, 2011.

2. Mapallil JJ., Basic dental materials, 3rd ed, Jaypee Brothers Medical Publisher (P), New Delhi, 2010.

3. Vivek R., Polyamides As A Denture Base Material - A Review, Journal of Dental and Medical Sciences, Volume 15, No.2: 119-121 (2016). DOI: 10.9790/0853-151208119121

4. ISO 20795-1: 2013.

5. Song SY, Kyoung SM, Jeong YL, Sang WS., Physical Properties and Color Stability of Injection-Molded Thermoplastic Denture Base Resins, The Journal of Advanced Prosthodontics, Volume 11: 32-40, (2019). DOI: 10.4047/JAP.2019.11.1.32.

6. Nguyena LG, Hilde M K, Marit Ø., Water Sorption, and Solubility of Polyamide Denture Base Materials, Acta Biomaterialia Odontologica Scandinavica, Volume 3, No.1: 47-52, (2017). DOI: $10.1080 / 23337931.2017 .1326009$.

7. Hemmati MA, et al., Watersorption and Flexural Strength of Thermoplastic and Conventional Heat-Polymerized Acrylic Resin, Journal of Dentistry, Volume 12, No.7: 478.484, (2015). PMID: 26877737

8. Singh K, Nidhi G., Injection Molding Technique for Fabrication of Flexible Prosthesis from Flexible Thermoplastic Denture base Materials. World Journal of Dentistry, Volume 3, No.4: 303-307, (2012). DOI: $10.5005 /$ jp-journals-10015-1178
9. Achilias DS et al. Material Recycling Trends and Perspective, Aristotic University of Thessaloniki, Greece, 2012.

10. Grigore ME., Methods of Recycling, Properties and Applications of Recycled Thermoplastic Polymers, MDPI Recycling, Volume 2, No.24: 1-11, (2017). DOI: $10.3390 /$ recycling2040024

11. Soja J, Norbert M., Degradation of Reinforced and Unreinforced Waste Polyamides During Mechanical Recycling, Hungarian Journal of Industry and Chemistry, Volume 4, No.2: 131-136, (2013). DOI:10.1515/513

12. Lumban Gaol EGL., Pengaruh Penambahan Nilon Termoplastik Murni Ke Dalam Nilon Daur Ulang Terhadap Kekuatan Transversal Basis Gigi Tiruan Nilon Termoplastik. Skripsi Kedokteran Gigi Program Sarjana Kedokteran Gigi, Universitas Sumatera Utara, Medan, 2016, Tidak Dipublikasikan.

13. Harahap UK., Pengaruh Penambahan Nilon Murni Pada Nilon Daurulang Terhadap Modulus Elastisitas Basis Gigi Tiruan Nilon Termoplastik. Skripsi Kedokteran Gigi Program Sarjana Kedokteran Gigi, Universitas Sumatera Utara, Medan, 2017, Tidak Dipublikasikan.

14. Çuvalci H, Kadir E, Hüseyin I., Investigation of the Effect of Glass Fiber Content on the Mechanical Properties of Cast Polyamide, Arab Journal for Science Engineering, Volume 39: 9049-9056, (2014). DOI: 10.1007/s13369-014-1409-8

15. Dikbas I, Ozlem G, Fatma U, Temel K., Impact strength of denture polymethyl methacrylate reinforced with different forms of E-glass fibers, Acta Odontologica Scandinavica, Volume 71: 727-732, (2013). DOI: 10.3109/00016357.2012.715198

16. Demir H, Oguzhan G, Arife D, Safa O., The Assessment of Impact Properties Of Denture Base Polymer Reinforced With Various Fibers, International Journal of academic research, Volume 9, No.1: 15-19, (2017). DOI: $10.7813 / 2075-4124.2017 / 9-1 / A .3$

17. Zhang M, Jukka PM.., E-Glass Fiber Reinforced Composites in Dental Application, Silicon, Volume 4:73-78, (2012). DOI: 10.1007/s12633-011-9075-x

18. Ariyani, Ismet DN, Harry A., Effect of Thermocycling And E-Glass Fiber Addition on Water Sorption And Color Stability of Thermoplastic Nylon Denture Base Material. IOSR Journal of Dental and medical science, Volume 15:41-48, (2016). DOI: 10.9790/0853-1508024148

19. Wieckiewicz M, Volker O, Gert R, Klaus WB., Research ArticlePhysical Properties of 
Polyamide-12 versus PMMADenture Base Material, Journal of Biomedicine and Biotechnology, Volume 2014: 1-8, (2014). DOI: $10.1155 / 2014 / 150298$

20. Meyabadi TF, Mohaddes MMR, Mousav Shoustari SA., Melt Spinning Of Reused Nylon 6: Structure And Physical Properties Of As-Spun, Drawn, And Texture Filaments. The Journal of the textile institute, Volume 101, No.6: $572-537$, (2010). DOI: $10.1080 / 00405000802561085$

21. Bucella M, Dorigato A, Pasqualini E., Thermo-mechanical properties of polyamide 6 chemically modified by chain extension with polyamide/ polycarbonate blend. Journal of Polymer Research, Volume 19, No. 9935: 1-9, (2012). DOI: 10.1007/s10965-012-9935-0

22. Balani K, Vivek V, Arvind A, Roger N., Bio surface A Material Science and Engineering Perspective, John Wiley and Sons, New Jersey, 2015.
23. Shokoohi S, Ahmad A, Ramin K. Silane Coupling Agent In Polymer-Based Reinforced Composite: A Review. Journal of reinforced plastic and composite, Volume 27, No.5: 473486,

(2008).

DOI: $10.1177 / 0731684407081391$

24. Frihi D et al. Crystallization of glass-fiberreinforced polyamide 66 composites: Influence of glass-fiber content and cooling rate. Composite science and technology, Volume 130: 70-77, (2016). DOI: 10.1016/j.compscitech.2016.05.007

25. Yoges V., Pengaruh Penambahan Serat Kaca Terhadap Penyerapan Air dan Kekuatan Transversal serta Modulus Elastisitas Bahan Basis Gigi Tiruan Nilon Termoplastik, Skripsi Kedokteran Gigi Program Sarjana Kedokteran Gigi, Universitas Sumatera Utara, Medan, 2015, Tidak Dipublikasikan. 